\title{
Treinamento em Primeiros Socorros para crianças com a utilização de um aplicativo
}

\author{
Aline Narcizo Gomes*, Ana Paula Boaventura.
}

\section{Resumo}

A Organização Mundial da Saúde recomendou o programa intitulado "Kids save lives" enfatizando que seja ensinado às crianças em idade escolar a prática de primeiros socorros. O aplicativo gratuito chama-se Primeiros Socorros, e tem como objetivo o treinamento em primeiros socorros para crianças. Projeto realizado em escola de ensino fundamental do município de Campinas - SP, os alunos usaram o app para os treinamentos práticos em manequins e responderam imediatamente um quizz interativo sobre cada cenário. Participaram 446 alunos com idade de seis a 14 anos, do ensino fundamental, cada treinamento teve duração média de 1h30' cada turma, totalizando 33 horas no período de 07 março a 01 junho de 2019. Em todas as respostas dos quizzes na avaliação imediatamente após o treinamento os alunos apresentaram em média $89 \%$ de respostas corretas. Conclui-se que na maioria das situações houve proporção significativa de acertos na realização do Quizz, sendo assim demonstrando que a utilização de um aplicativo como ferramenta de aprendizagem para crianças, possibilita o acesso a conhecimentos básicos de primeiros socorros essenciais para salvar vidas e minimizar possíveis sequelas.

\section{Palavras-chave:}

Primeiros socorros, smartphones, saúde escolar.

\section{Introdução}

As situações de urgência e emergência podem ocorrer em qualquer lugar e por isso necessitam de uma abordagem em primeiros socorros adequada. Para garantir uma abordagem adequada faz-se necessário que haja um treinamento de atendimento e disponibilidade e funcionalidade dos equipamentos a serem utilizados. ${ }^{1-2}$

Um aplicativo para smartphone voltado para o ensino em primeiros socorros no ambiente escolar, atendendo as especificações do desenvolvimento cognitivo da criança em idade escolar, pode ser considerado um método para se garantir uma formação em primeiros socorros mais eficaz tendo em vista o auxílio ao treinamento para atendimento e disponibilidade e funcionalidade dos equipamentos apropriados, como diz a recomendação da OMS.

Este projeto de pesquisa está vinculado ao projeto de extensão universitária intitulado como Primeiros socorros: preservando vidas e fortalecendo a comunidade nas urgências e emergências, desenvolvido nas escolas municipais desde 2016.

\section{Resultados e Discussão}

Trata-se de um estudo descritivo, exploratório que utilizou um aplicativo elaborado e desenvolvido em projeto anterior, disponível gratuitamente para iOS e Android em primeiros socorros que contribui como ferramenta interativa durante os treinamentos em urgências e emergências para crianças no ambiente escolar.

O estudo foi realizado em uma escola de ensino fundamental no Distrito de Barão Geraldo do município de Campinas - SP, com alunos regularmente matriculados do $1^{\circ}$. ao $9^{\circ}$. ano do ensino fundamental.

Foram apresentados e discutidos um cenário por vez, realizado o treinamento prático e em seguida a cada cenário os alunos foram divididos em grupos e responderam as perguntas do quizz do app nos tablets.
Tabela 1. Distribuição de respostas corretas e incorretas nos quizzes durante os treinamentos. Campinas, 2019.

\begin{tabular}{|c|c|c|}
\hline$n=466$ & $\begin{array}{l}\text { Corretas } \\
\text { n (\%) }\end{array}$ & $\begin{array}{l}\text { Incorretas } \\
\text { n (\%) }\end{array}$ \\
\hline \multicolumn{3}{|l|}{ Trauma } \\
\hline $\begin{array}{l}\text { Qual a primeira coisa a se fazer em uma situação de } \\
\text { trauma? }\end{array}$ & $442(94,8)$ & $24(5,15)$ \\
\hline $\begin{array}{l}\text { Qual situação não caracteriza uma situação que pode } \\
\text { gerar um trauma }\end{array}$ & $335(71,88)$ & $131(28,2)$ \\
\hline O que é um trauma? & $322(69,09)$ & $144(30,9)$ \\
\hline \multicolumn{3}{|l|}{ Engasgo } \\
\hline O que é um engasgo? & $449(96,33)$ & $17(3,67)$ \\
\hline $\begin{array}{l}\text { Qual é o lugar que se posiciona o polegar para realizar } \\
\text { a manobra de desengasgo? }\end{array}$ & $336(72,10)$ & $130(27,8)$ \\
\hline $\begin{array}{l}\text { O que não deve se fazer na manobra de desengasgo } \\
\text { em bebês menores de } 1 \text { ano? }\end{array}$ & $234(50,3)$ & $323(49,7)$ \\
\hline \multicolumn{3}{|l|}{ Convulsão } \\
\hline O que é Convulsão? & $426(91,41)$ & $40(8,58)$ \\
\hline $\begin{array}{l}\text { Qual é a primeira coisa a se fazer com a pessoa que } \\
\text { está tendo convulsão? }\end{array}$ & $410(88,0)$ & $56(12,0)$ \\
\hline $\begin{array}{l}\text { O que não deve se fazer com uma pessoa que está } \\
\text { tendo convulsão? }\end{array}$ & $396(84,97)$ & $70(15,02)$ \\
\hline \multicolumn{3}{|l|}{ Desmaio } \\
\hline O que é desmaio? & $409(87,76)$ & $57(12,23)$ \\
\hline O que deve ser feito com a pessoa que desmaia? & $438(94,00)$ & $28(6,00)$ \\
\hline O que não deve ser feito com a pessoa que desmaia? & $277(59,44)$ & $189(40,55)$ \\
\hline \multicolumn{3}{|l|}{ Parada Cardiorrespiratória } \\
\hline O que é uma parada cardiorrespiratória? & $451(96,78)$ & $15(3,21)$ \\
\hline $\begin{array}{l}\text { Como sabemos que a pessoa está tendo uma parada } \\
\text { respiratória? }\end{array}$ & $456(97,85)$ & $10(2,14)$ \\
\hline $\begin{array}{l}\text { O que devemos fazer em toda a parada } \\
\text { cardiorrespiratória? }\end{array}$ & $419(89,9)$ & $47(10,08)$ \\
\hline Quantas compressões deve se fazer em 1 minuto? & $436(93,56)$ & $30(6,43)$ \\
\hline O que é DEA? Quem pode usá-lo? & $430(92,27)$ & $36(7,72)$ \\
\hline O que o DEA faz? & $426(92,06)$ & $37(7,93)$ \\
\hline
\end{tabular}

\section{Conclusões}

Conclui-se que na maioria das situações houve proporção significativa de acertos na realização do quizz, sendo assim demonstrando que a utilização de um aplicativo como ferramenta de aprendizagem para crianças.

\section{Agradecimentos}

Agradecimento ao Programa de Bolsas de
Iniciação Científica PIBIC CNPQ/UNICAMP,
Quota-2018-2019

1.Bottiger BW, Aken HV. Kids save lives - Training school children in cardiopulmonary resuscitation worldwide is now endorsed by the World Health Organization (WHO). Official Journal of the European Resuscitation Council. 2015; 94:A5-A7. [acesso em 20 abr 2019]. Disponível em: https://doi.org/10.1016/j.resuscitation.2015.07.005. 